\title{
SIFAT-SIFAT TRANSFORMASI PROYEKTIF
}

\author{
PUTRI FAUZIAHTUL ASRI, HARIPAMYU, ZULAKMAL \\ Program Studi Matematika, \\ Fakultas Matematika dan Ilmu Pengetahuan Alam, Universitas Andalas, \\ Kampus Unand Limau Manis, Padang, Indonesia \\ email: putriauzi@gmail.com
}

\begin{abstract}
Abstrak. Transformasi yang memetakan $\mathbb{P}^{2}$ ke $\mathbb{P}^{2}$ disebut dengan transformasi proyektif. Pada transformasi ini, koordinat homogen sangat diperlukan dalam pembentukan matriks standar transformasi. Penelitian ini bertujuan untuk mengkaji sifat-sifat yang dimiliki oleh transformasi proyektif berdasarkan matriks standar transformasi yang terbentuk.
\end{abstract}

Kata Kunci: Bidang $\mathbb{P}^{2}$, transformasi proyektif, $P G L(2)$

$\begin{array}{lll}\text { Diterima } & : & 26 \text { Juli } 2018 \\ \text { Direvisi } & : & 17 \text { September } 2018 \\ \text { Dipublikasikan } & : & 21 \text { Desember 2018 }\end{array}$

\section{Pendahuluan}

Geometri proyektif mulai dipelajari pada abad ke-14. Geometri proyektif didasarkan pada masalah para seniman yang sulit melukiskan dua buah garis sejajar pada kanvas, sama halnya dengan memindahkan gambar realistik ke dalam sebuah bidang. Namun, pada awalnya ilmu ini kurang menarik jika dibandingkan dengan geometri analitik. [7]

Bidang pada geometri proyektif disebut dengan bidang proyektif $\mathbb{P}^{2}$. Pada bidang tersebut, definisi titik dan garis akan berbeda dengan titik pada umumnya, begitu pula dengan definisi garis. Definisi-definisi pada bidang $\mathbb{P}^{2}$ mempunyai kaitan dengan bidang bola $\mathbb{S}^{2}$, misalnya pasangan titik $(x,-x)$ adalah sebuah titik di $\mathbb{P}^{2}$ dimana $x$ dan $-x$ merupakan pasangan titik yang saling antipodal di $\mathbb{S}^{2}$. [5].

Pada bidang proyektif, koordinat homogen sangat diperlukan dalam pembentukan suatu matriks standar transformasi. Transformasi pada bidang proyektif tersebut, disebut sebagai transformasi proyektif dimana $\mathbb{P}^{2}$ akan di petakan ke $\mathbb{P}^{2}$. Selain itu, semua transformasi proyektif yang memenuhi sifat kolineasi akan membentuk suatu grup yang disebut dengan $P G L(2)$ [5]. Maka dari itu, pada penelitian ini akan dijelaskan tentang pembentukan transformasi proyektif di $\mathbb{P}^{2}$ beserta sifatsifatnya. 


\section{Landasan Teori}

\subsection{Grup}

Definisi 2.1. [1] Suatu grup $\langle G, *\rangle$ adalah suatu himpunan tak kosong $G$ yang bersifat tertutup terhadap suatu operasi biner *, sedemikian sehingga memenuhi aksioma-aksioma berikut :

(1) Operasi biner $*$ bersifat asosiatif.

(2) Terdapat suatu elemen $e \in G$, sedemikian sehingga $e * x=x * e=x$ untuk setiap $x \in G$. (Elemen e adalah elemen identitas terhadap operasi $*$ pada $G$ ).

(3) Untuk setiap $a \in G$, terdapat $a^{-1} \in G$, sedemikian sehingga $a a^{-1}=a^{-1} a=$ e.(Elemen $a^{-1}$ adalah invers dari a terhadap operasi $*$ ).

\subsection{Relasi Ekuivalen}

Definisi 2.2. [4] Misalkan X adalah suatu himpunan tak kosong. Suatu relasi pada himpunan $X$ dikatakan relasi ekuivalen apabila bersifat:

(1) Refleksi, yaitu $x \sim x$ untuk semua $x \in X$.

(2) Simetri, yaitu jika $x \sim y$ maka $y \sim x$ untuk semua $x, y \in X$.

(3) Transitif, yaitu jika $x \sim y$ dan $y \sim z$ maka $x \sim z$ untuk semua $x, y, z \in X$.

Definisi 2.3. [4] Misalkan $\sim$ adalah relasi ekuivalen pada $X$, maka kelas ekuivalen dari $x \in X$ ditulis $[x]$ adalah himpunan semua $y \in X$ sedemikian sehingga $y \sim x$, ditulis:

$$
[x]=\{y \in X \mid y \sim x\}
$$

\subsection{Terminologi Ruang Vektor}

(1) Misalkan $B=\left\{v_{1}, v_{2}, \cdots, v_{n}\right\}$ suatu basis terurut untuk $V$ dan $w \in V$. Jika $w=a_{1} v_{1}+a_{2} v_{2}+\cdots+a_{n} v_{n}$ maka $\left(a_{1}, a_{2}, \cdots, a_{n}\right)$ adalah koordinat dari $w$ yang berkaitan dengan basis $B$ biasa ditulis

$$
(w)_{B}=\left(\begin{array}{c}
a_{1} \\
a_{2} \\
\vdots \\
a_{n}
\end{array}\right) .
$$

(2) Suatu (standar) hasil kali dalam atau juga disebut sebagai perkalian titik dari $u$ dan $v$, adalah suatu bilangan riil

$$
u \cdot v=u^{T}=x_{1} y_{1}+x_{2} y_{2}+\cdots+x_{n} y_{n} .
$$

Untuk hasil kali dalam dua buah vektor $u$ dan $v$ biasa ditulis dengan notasi $\langle u, v\rangle$.

(3) Hubungan antara panjang vektor dengan hasil kali dalam vektor dapat ditulis

$$
|x|=\langle x, x\rangle^{\frac{1}{2}}
$$


(4) Jika $u=u_{1} i+u_{2} j+u_{3} k$ dan $v=v_{1} i+v_{2} j+v_{3} k$ adalah vektor-vektor di $\mathbb{R}^{3}$, hasil kali silang $u \times v$ didefinisikan sebagai suatu vektor di $\mathbb{R}^{3}$ dengan

$$
u \times v=\left(v_{2} v_{3}-v_{3} v_{2}\right) i+\left(v_{3} v_{1}-v_{1} v_{3}\right) j+\left(v_{1} v_{2}-v_{2} v_{1}\right) k=\left|\begin{array}{ccc}
i & j & k \\
u_{1} & u_{2} & u_{3} \\
v_{1} & v_{2} & v_{3}
\end{array}\right|
$$

Teorema 2.4. [5] The Vector Triple Product Formula. Misalkan $u, v, w \in \mathbb{R}^{3}$, maka

$$
(u \times v) \times w=\langle u, w\rangle v-\langle v, w\rangle u .
$$

\subsection{Nilai Eigen dan Vektor Eigen}

Definisi 2.5. [3] Misalkan $T: V \rightarrow V$ adalah suatu transformasi linear. Jika $v \in V$ adalah vektor tak nol dan terdapat skalar $k$ sehingga $T(v)=k v$, maka $v$ dikatakan suatu vektor eigen dari $T$. Dan skalar $k$ dikatakan suatu nilai eigen dari $T$ yang berkaitan dengan vektor eigen $v$.

\subsection{Geometri Pada Permukaan Bola}

\section{Bidang Euclid $\mathbb{E}^{3}$}

Bidang Euclid $\mathbb{E}^{3}$ digunakan untuk menyatakan himpunan $\mathbb{R}^{3}$ yang dilengkapi dengan jarak antara dua buah titik. Misalkan $P$ dan $Q$ adalah dua buah titik, maka didefinisikan jarak $P$ dan $Q$ dengan

$$
d(P, Q)=|Q-P| .
$$

Didefinisikan sebuah arah sebagai himpunan semua vektor-vektor yang proporsional yang tak nol, diberikan vektor $v$ maka

$$
[v]=\{t v \mid t \in \mathbb{R}\} .
$$

Jika $P$ adalah sebarang titik dan $v$ adalah vektor tak nol,maka

$$
l=\{X \mid X-P \in[v]\}
$$

dikatakan sebagai suatu garis yang melewati $P$ dengan arah $[v]$.

Misalkan suatu transformasi $T$ memetakan suatu titik $X$ ke titik $X, T X=X$, maka $X$ disebut sebagai titik tetap dari transformasi $T$. Jika $l$ adalah suatu garis yang memenuhi $T l=l$, maka $l$ disebut sebagai garis tetap dari transformasi $T$.[5]

\section{Bidang Bola $\mathbb{S}^{2}$}

Pada geometri bola, definisi garis berbeda dengan definisi garis pada umumnya. Suatu bidang permukaan bola $\mathbb{S}^{2}$ secara umum di definisikan

$$
\mathbb{S}^{2}=\left\{x \in \mathbb{E}^{3}|| x \mid=1\right\} .
$$




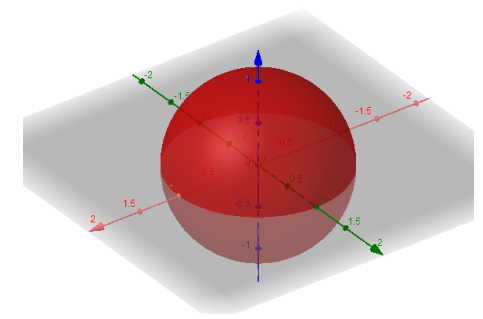

Gambar 1. Bidang $\mathbb{S}^{2}$

Definisi 2.6. [5] Misalkan $\xi \in \mathbb{E}^{3}$ adalah suatu vektor satuan. Maka

$$
l=\left\{x \in \mathbb{S}^{2} \mid\langle\xi, x\rangle=0\right\} .
$$

adalah suatu garis dengan kutub $\xi$.

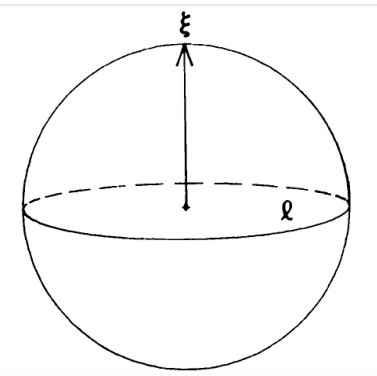

Gambar 2. Garis $l$ dengan kutub $\xi$

Dua buah titik $P$ dan $Q$ di $\mathbb{S}^{2}$ dikatakan saling antipodal jika $P=-Q$.

Teorema 2.7. [5] Misalkan $P$ dan $Q$ dua titik yang berbeda di $\mathbb{S}^{2}$ yang tidak saling antipodal. Maka terdapat garis tunggal yang melewati $P$ dan $Q$ yang dinotasikan dengan $\overline{P Q}$.

Teorema 2.8. [5] Misalkan $l$ dan $m$ dua garis yang berbeda di $\mathbb{S}^{2}$. Maka l dan $m$ berpotongan pada dua titik dimana dua titik tersebut saling antipodal

\section{Pembahasan}

\subsection{Bidang Proyektif $\mathbb{P}^{2}$}

Definisi 3.1. [5] Bidang Proyektif $\mathbb{P}^{2}$ adalah himpunan semua pasangan $\{x,-x\}$ dengan $x \in \mathbb{S}^{2}$.

$$
\mathbb{P}^{2}=\left\{(x,-x) \mid x \in \mathbb{S}^{2}\right\}
$$

Pernyataan berikut ekuivalen dengan definisi $\mathbb{P}^{2}$. 
(1) Himpunan semua garis yang melewati titik asal di $\mathbb{E}^{3}$.

(2) Himpunan dari semua kelas ekuivalen dari tiga bilangan terurut $\left(x_{1}, x_{2}, x_{3}\right)$ yang tidak semuanya nol, $\left(x_{1}, x_{2}, x_{3}\right) \neq(0,0,0)$, dimana dua vektor ekuiva-len jika mereka proporsional.[5]

Misalkan $\pi: \mathbb{S}^{2} \rightarrow \mathbb{P}^{2}$ adalah pemetaan yang memetakan setiap $x$ di $\mathbb{S}^{2}$ ke $\{x,-x\}$. Sebuah garis di $\mathbb{P}^{2}$ adalah himpunan yang berbentuk $\pi l$ dimana $l$ adalah garis di $\mathbb{S}^{2}$. Jika $\xi$ adalah kutub dari $l$, maka $\pi \xi$ dinamakan kutub dari $\pi l$.

$$
\pi l=\left\{\pi x \in \mathbb{P}^{2} \mid\langle\pi x, \pi \xi\rangle=0\right\} .
$$

Teorema 3.2. [5] Sifat Insidensi pada $\mathbb{P}^{2}$

(1) Dua garis berbeda pada $\mathbb{P}^{2}$ tepat berpotongan pada satu titik.

(2) Dua titik pada $\mathbb{P}^{2}$ tepat berada pada satu garis.

Misalkan $\left\{\mathbf{e}_{1}, \mathbf{e}_{2}, \mathbf{e}_{3}\right\}$ adalah basis di $\mathbb{R}^{3}$, maka setiap vektor $x \in \mathbb{R}^{3}$ dapat ditulis sebagai kombinasi linear dari $\mathbf{e}_{1}, \mathbf{e}_{2}, \mathbf{e}_{3}$ yaitu

$$
x=x_{1} \mathbf{e}_{1}+x_{2} \mathbf{e}_{2}+x_{3} \mathbf{e}_{3} .
$$

Jika $\pi x$ adalah sebuah titik di $\mathbb{P}^{2}, \lambda$ adalah suatu bilangan riil tak nol dan

$$
\lambda x=u_{1} \mathbf{e}_{1}+u_{2} \mathbf{e}_{2}+u_{3} \mathbf{e}_{3},
$$

maka $\left(u_{1}, u_{2}, u_{3}\right)$ dinamakan koordinat homogen dari $\pi x$

Teorema 3.3. [5] Misalkan $P, Q, R$, dan $S$ empat titik di $\mathbb{P}^{2}$ dan tidak ada tiga titik diantaranya yang kolinear. Maka terdapat basis di $\mathbb{R}^{3}$ sedemikian sehingga keempat titik $P, Q, R$ dan $S$ mempunyai koordinat yang berkaitan dengan basis tersebut.

Dari teorema di atas akan didapatkan koordinat $(1,0,0),(0,1,0),(0,0,1)$ dan $(1,1,1)$ mewakili titik $P, Q, R$ dan $S$ berturut-turut.

\subsection{Transformasi Proyektif}

Transformasi yang memetakan titik di $\mathbb{P}^{2}$ ke $\mathbb{P}^{2}$ disebut sebagai transformasi proyektif. Secara umum peta dari transformasi proyektif adalah perkalian matriks $3 \times 3$

$$
\left(\begin{array}{lll}
a & b & c \\
d & e & f \\
g & h & i
\end{array}\right)
$$

yang memiliki invers dengan titik di $\mathbb{P}^{2} \cdot[2]$

Teorema 3.4. [2] Suatu transformasi proyektif memetakan titik-titik yang kolinear menjadi titik-titik yang kolinear.

Definisi 3.5. [5] Suatu kolineasi adalah sebuah pemetaan bijektif $T: \mathbb{R}^{3} \rightarrow \mathbb{R}^{3}$ yang memenuhi kondisi untuk tiga titik yang berbeda dan kolinear jika dan hanya jika peta dari tiga titik kolinear tersebut kolinear. 
Teorema 3.6. [5] Himpunan dari semua kolineasi di $\mathbb{P}^{2}$ membentuk suatu grup, disebut dengan grup proyektif (PGL(2)).

Teorema 3.7. [5] Teorema Fundamental Bidang Proyektif. Misalkan PQRS dan PQRS adalah segiempat (empat titik yang tidak segaris). Maka terdapat transformasi tunggal $T$ dimana $T \in P G L(2)$ sedemikian sehingga $T P=P^{\prime}, T Q=$ $Q^{\prime}, T R=R^{\prime}$ dan $T S=S^{\prime}$.

Bukti. Misalkan transformasi $T$

$$
\begin{aligned}
& T: \mathbb{P}^{2} \rightarrow \mathbb{P}^{2} \\
& T(x)=M x
\end{aligned}
$$

Pilih koordinat homogen $(1,0,0),(0,1,0),(0,0,1)$, dan $(1,1,1)$ sebagai titik $P, Q, R$, dan $S$ berturut-turut. Maka matriks $M$ diisi dengan vektor $P^{\prime}, Q^{\prime}$ dan $R^{\prime}$ berturutturut, dimisalkan dengan $x, y$, dan $z$. Matriks $M$ menjadi

$$
M=\left(\begin{array}{lll}
x_{1} & y_{1} & z_{1} \\
x_{2} & y_{2} & z_{2} \\
x_{3} & y_{3} & z_{3}
\end{array}\right)
$$

Selanjutnya untuk hasil transformasi titik $\mathrm{P}, \mathrm{Q}$ dan $\mathrm{R}$ sudah jelas bahwa $T P=$ $P^{\prime}, T Q=Q^{\prime}, T R=R^{\prime}$. Sedangkan untuk hasil transformsi titik $S$

$$
\left(\begin{array}{lll}
x_{1} & y_{1} & z_{1} \\
x_{2} & y_{2} & z_{2} \\
x_{3} & y_{3} & z_{3}
\end{array}\right)\left(\begin{array}{l}
1 \\
1 \\
1
\end{array}\right)=\left(\begin{array}{l}
x_{1}+y_{1}+z_{1} \\
x_{2}+y_{2}+z_{2} \\
x_{3}+y_{3}+z_{3}
\end{array}\right)
$$

Untuk sebarang $\lambda, \mu$ dan $\nu$ yang tak nol berlaku

$$
\left(\begin{array}{lll}
\lambda x_{1} & \mu y_{1} & \nu z_{1} \\
\lambda x_{2} & \mu y_{2} & \nu z_{2} \\
\lambda x_{3} & \mu y_{3} & \nu z_{3}
\end{array}\right)\left(\begin{array}{l}
1 \\
1 \\
1
\end{array}\right)=\left(\begin{array}{c}
\lambda x_{1}+\mu y_{1}+\nu z_{1} \\
\lambda x_{2}+\mu y_{2}+\nu z_{2} \\
\lambda x_{3}+\mu y_{3}+\nu z_{3}
\end{array}\right),
$$

sehingga matriks standar transformasi $M$ yang berkaitan dengan $P, Q, R$ dan $S$ adalah

$$
\left(\begin{array}{lll}
\lambda x_{1} & \mu y_{1} & \nu z_{1} \\
\lambda x_{2} & \mu y_{2} & \nu z_{2} \\
\lambda x_{3} & \mu y_{3} & \nu z_{3}
\end{array}\right)
$$

Transformasi $T$ dengan matriks transformasi $\mathrm{M}$ jelas merupakan fungsi bijektif sehingga $T \in P G L(2)$.

Selanjutnya akan dibuktikan ketunggalan transfomasi $T$. Misalkan dipilih koordinat homogen yang berbeda dari sebelumnya, yaitu $(1,0,0),(0,1,0),(0,0,1)$, dan $(-1-, 1,1)$ dan menyatakan titik $P, Q, R$ dan $S$ berturut-turut. Karena hanya pada titik $S$ yang berbeda, maka akan dilihat hasil transformasi dari titik $S$.

$$
\left(\begin{array}{lll}
x_{1} & y_{1} & z_{1} \\
x_{2} & y_{2} & z_{2} \\
x_{3} & y_{3} & z_{3}
\end{array}\right)\left(\begin{array}{r}
-1 \\
-1 \\
1
\end{array}\right)=\left(\begin{array}{l}
-x_{1}-y_{1}+z_{1} \\
-x_{2}-y_{2}+z_{2} \\
-x_{3}-y_{3}+z_{3}
\end{array}\right)
$$


dan untuk sebarang $\alpha, \beta, \gamma$ yang tak nol

$$
\left(\begin{array}{lll}
\alpha x_{1} & \beta y_{1} & \gamma z_{1} \\
\alpha x_{2} & \beta y_{2} & \gamma z_{2} \\
\alpha x_{3} & \beta y_{3} & \gamma z_{3}
\end{array}\right)\left(\begin{array}{r}
-1 \\
-1 \\
1
\end{array}\right)=\left(\begin{array}{l}
-\alpha x_{1}-\beta y_{1}+\gamma z_{1} \\
-\alpha x_{2}-\beta y_{2}+\gamma z_{2} \\
-\alpha x_{3}-\beta y_{3}+\gamma z_{3}
\end{array}\right)
$$

Sehingga matriks standar transformasi $N$ yang berkaitan dengan $P, Q, R$ dan $S$ adalah

$$
\left(\begin{array}{lll}
\alpha x_{1} & \beta y_{1} & \gamma z_{1} \\
\alpha x_{2} & \beta y_{2} & \gamma z_{2} \\
\alpha x_{3} & \beta y_{3} & \gamma z_{3}
\end{array}\right)
$$

Matriks $M$ dengan $N$ adalah matriks yang sama pada transformasi proyektif (yang menggunakan bidang proyektif) karena $N$ merupakan kelipatan dari $M$. Sehinggga terbukti bahwa transformasi $T$ tunggal di $\mathbb{P}^{2}$.

Teorema 3.8. [5] Setiap transformasi proyektif memiliki paling sedikit satu titik tetap dan satu garis tetap.

Bukti. Misalkan $T: \mathbb{P}^{2} \rightarrow \mathbb{P}^{2}$ suatu transformasi proyektif yang didefinisikan sebagai

$$
T([x])=M[x]
$$

Akan terdapat suatu vektor tak nol $x \in \mathbb{R}^{3} \backslash\{(0,0,0)\}$ dari $T$ untuk nilai eigen $\lambda$ yang berkaitan. Transformasi $T$ dapat ditulis sebagai

$$
T(x)=M x=\lambda x
$$

dengan $x$ adalah koordinat homogen dari $[x]$. Karena vektor $x \neq \overrightarrow{0}$ maka $\operatorname{det}(M-$ $I \lambda)=0$. Selanjutnya, karena $(M-I \lambda)$ merupakan matriks $3 \times 3$ maka terdapat nilai eigen dari matriks $M$. Karena matriks $M$ memiliki sebuah nilai eigen maka transformasi ini juga memiliki vektor eigen yang tak nol yang berkaitan dengan nilai eigen tersebut.

Misalkan nilai eigen yang didapatkan $\lambda_{1}$ dan vektor eigen yang berakitan dengan $\lambda_{1}$ adalah $v_{1}$ maka

$$
T\left(v_{1}\right)=\lambda_{1} v_{1}
$$

Titik $v_{1}$ dan $\lambda v_{1}$ adalah titik yang sama pada bidang proyektif karena berada pada kelas ekuivalen yang sama. Sehingga dapat disimpulkan bahwa vektor eigen $v_{1}$ berperan sebagai titik tetap dan terbukti bahwa setiap transformasi proyektif mempunyai minimal satu titik tetap.

Selajutnya, misalkan $\pi \xi$ adalah kutub dari garis $\pi l$ dimana

$$
\pi l=\left\{\pi x \in \mathbb{P}^{2} \mid\langle\pi x, \pi \xi\rangle=0\right\} .
$$

Titik $\pi x$ merupakan kelas ekuivalen dari $x$ atau ditulis $[x]$. Ambil sebarang $[x]$ di $\pi l$. Jika $T$ adalah suatu transformasi proyektif maka

$$
\begin{aligned}
T([x]) & =M([x]) \\
& =[M x]
\end{aligned}
$$


Akan ditunjukkan bahwa $\langle\xi, M x\rangle=0$. Misalkan $[x]$ adalah titik tetap yang telah didapatkan sebelumnya. Pilih $\xi=(1,0,0)$ sehingga $[x]$ berbentuk $[(0, a, b)]$. Karena $[x]$ adalah titik tetap maka berlaku $\langle M x, \xi\rangle=0$. Perhatikan bahwa

$$
\begin{aligned}
\langle M x, \xi\rangle & =(M x)^{T} \xi \\
\Longleftrightarrow 0 & =x^{T} M^{T} \xi \\
\Longleftrightarrow 0 & =\left\langle x, M^{T} \xi\right\rangle
\end{aligned}
$$

Karena $x=(0, a, b)$ maka $M^{T} \xi$ haruslah berbentuk $(s, 0,0)$ untuk $s \in \mathbb{R} \backslash\{0\}$.

Untuk titik-titik yang lain pada $\pi l$ yang tegak lurus teradapa $\pi l$ misalkan $y$ berlaku

$$
\begin{aligned}
\langle M y, \xi\rangle & =(M y)^{T} \xi \\
& =0
\end{aligned}
$$

Dengan demikian, untuk setiap transformasi dari $\pi l,\langle[M x], \xi\rangle=0$ sehingga garis $\pi l$ menjadi garis tetap.

Terbukti bahwa setiap transformasi proyektif memiliki paling sedikit satu titik tetap dan satu garis tetap.

Contoh 3.9. [7] Misalkan transformasi pada isometri bola $T: E^{3} \rightarrow E^{3}$ yang didefinisikan

$$
A=\left(\begin{array}{rrr}
0 & -1 & 0 \\
1 & 0 & 0 \\
0 & 0 & -1
\end{array}\right)
$$

Transformasi ini digunakan untuk pencerminan rotasi yaitu dirotasikan sebesar 90 derajat terhadap sumbu- $z$ dan dicerminkan teradap bidang- $x y$ pada bidang bola $\mathbb{S}^{2}$. Pada transformasi ini tidak terdapat titik tetap. Misalkan titik $(0,0,1)$ ditransformasikan maka diperoleh titik $(0,0,-1)$ sehingga terlihat bahwa tidak terdapat titik tetap. Akan tetapi, jika dikaji pada bidang proyektif $\mathbb{P}^{2}$ dua titik tersebut merupakan titik yang sama. Sehingga dapat dikatakan bahwa $(0,0,1)$ merupakan titik tetap pada $\mathbb{P}^{2}$ dan juga garis $[0,0,1]$ merupakan garis tetap pada $\mathbb{P}^{2}$.

\section{Daftar Pustaka}

[1] Fraleigh, John B and Victor Katz. 1967. A First Course in Abstract Algebra. Addison-Wesley Publishing Company, New York.

[2] Gebert, Jurgen Rochter. 2010. Perspective on Projective Geometry. Springer, New York.

[3] Jacob, Bill. 1990. Linear Algebra. W.H Freeman and Company, New York.

[4] Lee, John M.. 2013. Introduction to Smooth Manifold Second Edition. Springer, New York.

[5] Ryan, Patrick J. 1986. Euclidean and Non Euclidean Geometry. Cambridge University, New York.

[6] Shores, Thomas S. 1999. Applied Linear Algebra And Matrix Analysis. Springer, New York. 
Sifat-Sifat Transformasi Proyektif 135

[7] Sibley, Thomas Q. 1998. The Geometric View Point: A Survey in Geo-metries. Addison Wesley Higher Math, New York. 